ISSN: 2238-8052

\title{
MOVIMENTOS SOCIAIS: UMA SÍNTESE VISANDO À RETOMADA DO SEU PAPEL TRANSFORMADOR ${ }^{1}$
}

\author{
LES MOUVEMENTS SOCIAUX: UNE SYNTHÈSE VISANT À LA REPRISE DE SON RÔLE \\ TRANSFORMATEUR
}

Cláudio Jorge Moura de CASTILHO²

Artigo recebido em 23/10/2017 e aceito em 20/11/2017

Palavras-chave:

Política

Estado

Sociedade

Lutas Sociais

Território

\section{Mots-clés:}

Politique

État

Société

Luttes Sociales

Territoire

\section{R E S U M O}

Este artigo propõe fazer uma síntese das principais ideias que têm norteado os movimentos sociais no Brasil, através de ações observadas em Recife, visando recuperar seu potencial "transformador" da sociedade. Identificou-se, portanto, um conjunto de três experiências de movimentos sociais: a dos movimentos tradicionais, a dos novos movimentos sociais e a dos movimentos mais difusos e descentralizados. Metodologicamente, utilizamo-nos do que se vem observando, ultimamente, no pensar e atuar em termos dos movimentos sociais, consultando, quando necessário, fontes teóricas e ouvindo militantes durante protestos de rua. 0 principal resultado ao qual chegamos reside no fato de que há, atualmente, uma enorme diversidade em termos de movimentos sociais coexistindo no tempo-espaço, os quais devem ser somados numa perspectiva de se buscar soluções que atendam os interesses de todos e de todas as pessoas que deles participam.

\section{R É S U M É}

Cet article propose de faire une synthèse des principales idées qui ont guidé les mouvements sociaux au Brésil, au travers d'actions remarquées à Recife, afin de mettre en évidence leur potentiel de transformation de la société. On a identifié un ensemble de trois expériences de mouvements sociaux: celui des mouvements traditionnels, celui des nouveaux mouvements sociaux et celui des mouvements plus diffus et décentralisés. Sur le plan méthodologique, nous avons utilisé ce qui a été observé récemment, en ce qui concerne la pensée et la practique en termes de mouvements sociaux, en consultant, lorsque nécessaire, des sources théoriques et en écoutant les militants lors des manifestations de rue. Le principal résultat auquel nous sommes arrivés réside dans le fait qu'il y a, actuellement, une grande diversité en termes de mouvements sociaux coexistant dans l'espace-temps, ce qui doit être valorisé dans son ensemble en vue de trouver des solutions qui conviennent à tous.

\footnotetext{
1 A realização deste texto foi pensada em função da necessidade que sentimos, a partir de uma entrevista concedida a professores e alunos do Colégio Fazer Crescer - uma escola privada localizada em área de classe média alta na cidade de Recife - de se ter uma síntese didática no que concerne às inter-relações entre os movimentos sociais e a sociedade, segundo às vicissitudes do tempo-espaço capitalista influindo na dinâmica social do mundo contemporâneo, a partir de experiências locais.

2 Professor Associado do Departamento de Ciências Geográficas da Universidade Federal de Pernambuco, Coordenador do Grupo de Pesquisa Movimentos Sociais e Espaço Urbano, Bolsista de produtividade nível 1D do CNPq. E-mail: claudiocastilho44@gmail.com.
} 


\section{INTRODUÇÃo}

Antes de tudo, acreditamos que sem movimentos sociais não há possibilidade concreta de se produzir uma sociedade, pelo menos, diferente da existente, e isto porque são as suas ações que carregam a criatividade e a inovação em termos do pensar e atuar permanentemente no mundo. E a própria história dos homens e das mulheres no tempo-espaço tem mostrado o quanto o diferente - em termos, por exemplo, da produção de territórios na cidade e no campo, fazendo valer os desejos e as necessidades de caráter mais humano - foi resultado dos movimentos sociais.

Isso se faz verdadeiro, sobretudo, porque, por mais que se possa pensar e dizer o contrário, a sociedade, no geral, nunca se cala, visto que sempre, sob o capitalismo perverso que se tem concretizado e se consolidado de maneira cada vez mais forte no mundo, as desigualdades e as injustiças territoriais, reproduzem-se, ampliam-se e mantêm-se no tempo-espaço geográfico.

Com efeito, mais cedo ou mais tarde, as pessoas sempre se autoconscientizam de que o mundo que se lhes aparece é irreal. Em outras palavras, em princípio, uma realidade que parece perfeita e promissora é, na verdade, na acepção de Santos (2000), uma "fábula" elaborada e propagada como algo que existe sem existir de fato. Esta irrealidade - sustentada pelo falso discurso do progresso ou do desenvolvimento apresentados como alto em beneficio de todos e de todas - é percebida, suscitando reações - protestos, mobilizações, ações, etc. - dos homens e das mulheres preteridos pelos benefícios promovidos pelo crescimento econômico, muitas das quais passam a constituírem movimentos sociais.

Porém, frente a tais reações, as classes sociais hegemônicas, nas diversas escalas do acontecer histórico do capitalismo, têm agido nitidamente no sentido de negar e, mesmo, criminalizar os movimentos sociais. Isto tem acontecido mediante a utilização da mídia oficial, a qual, por sua vez, se acha comprometida com a expansão dos interesses econômicos inerentes à lógica da racionalidade técnico-instrumental neoliberal. 0 que, aliás, não acontece por acaso, mas porque elas sabem que, sobretudo, quando fortes, os movimentos sociais são capazes de mudar qualquer situação, inclusive, algumas vezes, conseguindo a concessão de conquistas da parte do Estado.

Daí a necessidade de recolocar a problemática em torno dos movimentos sociais, retomando alguns dos seus principais conceitos (primeira seção deste escrito); suas principais estratégias de ação (segunda seção); e sua relação com o Estado (terceira seção), instituição que, quer se queira ou não, ainda deve ser reconhecida como a única capaz de regular os interesses de classe na sociedade.

A metodologia utilizada para a concretização deste artigo fundamentou-se, mormente, no conhecimento teórico e na experiência empírica do autor do presente escrito, a partir do diálogo promovido com ideias da parte dos intelectuais que se debruçaram sobre o assunto e com a prática dos movimentos sociais a partir das suas territorialidades e fazendo os seus diversos tipos de protestos nas ruas. 
Diante de tal opção metodológica, escolhemos como fontes principais da observação realizada escritos e falas de pessoas na sua vida cotidiana em atos de protesto e manifestação nas ruas. 0 diálogo com a produção acadêmica foi realizado na medida em que sentimos a necessidade de aproximar empiria e teoria ${ }^{3}$, visando contribuir para a concretização de uma filosofia da práxis.

Portanto, as teorias foram aparecendo na presente reflexão - mediante as citações feitas ao longo do texto - na medida em que julgamos necessário retomá-las na nossa discussão. E isto independentemente da vertente ideológica dos autores visto que, sempre, tentamos, na perspectiva de concretizar uma síntese a partir da realização da unidade na diversidade, proporcionar o diálogo dos vários saberes e conhecimentos inerentes à nossa sociedade. A respeito desta nossa intenção, fundamentando-se no legado marxiano, escreveu Harvey (2004, p. 103) que

0 trabalho de síntese das múltiplas lutas hoje existentes tem de ser permanente, pois os campos e terrenos em que essas lutas se travam, e as questões a que respondem, estão em perpétua mudança, acompanhando as alterações da dinâmica capitalista e das condições globais associadas. A frase [...] 'defesa e promoção de certos interesses particulares, adequadamente unificados como maneira de fornecer bases ao 'interesse geral' é portanto a tarefa essencial a ser empreendida.

Ademais, como ações históricas decorrentes de lutas sociais que devem ser, permanentemente, revistas e refletidas teórica e metodologicamente, os movimentos sociais vão continuar acontecendo enquanto houverem problemas de desigualdades territoriais a serem resolvidos. Por isto que, escrevera Gohn (1997, p. 20),

Enquanto a humanidade não resolver seus problemas básicos de desigualdades sociais, opressão e exclusão, haverá lutas, haverá movimentos. E deverá haver teorias para explicá-los: esta é a nossa principal tarefa e responsabilidade, como intelectuais e cidadãos engajados na luta por transformações sociais em direção a uma sociedade mais justa e livre.

E, parece-nos, que os problemas relativos às desigualdades territoriais não deixarão de existir tão cedo, sobretudo porque eles se acham inerentes à própria lógica vigente de produção dos territórios, a qual ainda se calca nos três pilares básicos que sustentam, há séculos de existência, as relações sociais capitalistas de produção: a exploração do trabalho, ou melhor, das classes que vivem do trabalho; a busca do crescimento econômico a todo custo, mesmo que desrespeitando os territórios vividos e a natureza; e a obtenção do lucro.

Contudo, dialeticamente, acreditamos que existem possibilidades na própria realidade de produção dos espaços de, pelo menos, fazer algo diferente, para o que os movimentos sociais constituem atores fundamentais. Acrescentamos, ainda, que, tal como havia pensado Santos (2000), o diferente - e talvez o radicalmente diferente - em termos de produção social do espaço geográfico acha-se na pobreza, na vida cotidiana das classes sociais que sofrem, "nos de baixo". Isto porque são

\footnotetext{
3 Para um maior aprofundamento acerca dos paradigmas teórico-metodológicos que embasaram muitos dos movimentos sociais no curso dos seus processos de luta pela mudança social, há várias leituras a se fazer seja no âmbito da sociologia seja no da geografia. Todavia, indicamos, respectivamente, dois trabalhos: o de Gohn (1997) e o de Pontes (2015).
} 
estas classes que, justamente por viverem as carências, possuem as condições efetivas para apontar o que fazer em seu benefício e, por sua vez, fazendo valer a complexidade da vida humana.

Com isso, pretendemos reforçar a ideia de que os movimentos sociais procedentes dos que sofrem possuem, efetivamente, um papel transformador na sociedade; muito embora tenhamos que refletir sobre o caráter deste papel transformador - e mesmo revolucionário - no mundo de hoje. 0 que deve ser feito, buscando elucidar a complexidade das inter-relações dos seus protagonistas no âmbito do processo de mudança e desmanchando os mitos, as fábulas e as mentiras seja da parte dos criminalizadores dos movimentos sociais, seja da parte dos esquerdistas ortodoxos que se perderam no tempo-espaço.

\section{RETOMADA DE CONCEITOS COM BASE NA PRÁTICA SOCIAL NO TERRITÓRIO}

Para simplificar a nossa reflexão, tentamos conceituar, a partir do que conseguimos perceber nas ruas (durante protestos realizados em espaços da cidade do Recife no curso da nossa vida) e em debates acadêmicos (na literatura sobre o assunto), três ideias básicas sobre os movimentos sociais, as quais se têm repetido ao longo da história: a que nos remete aos movimentos sociais tradicionais de cunho ortodoxo, a partir do que se destacou a necessidade de se ter uma vanguarda norteadora dos rumos a serem seguidos; a dos novos movimentos sociais realizados em torno de lideranças próprias saídas dos seus territórios e independentes de vanguardas externas aos territórios nos quais os movimentos acontecem; e a dos movimentos - quase que excessivamente autônomos descentralizados e difusos no espaço, sem lideranças bem definidas, apresentando certa confusão quanto à transparência dos seus objetivos.

No que diz respeito à primeira ideia, ressaltamos que, no começo, as ações relativas aos movimentos sociais achavam-se sob a tutela de instituições sociais tais como, principalmente, o Estado, os Partidos Políticos, os Sindicatos e a Igreja (nas suas variadas orientações em termos de credo religioso) que constituíam as chamadas forças vanguardistas tradicionais da revolução, as quais lhes deveriam proporcionar o suporte necessário visando apoiar as suas atividades.

Isso, ainda hoje, para os defensores da referida ideia, deve acontecer, muitas vezes, seguindo parâmetros teóricos e metodológicos de interpretação do conteúdo do Manifesto do Partido Comunista. No que concerne, em específico, a este documento, se por um lado, há que se ter cuidado com algumas colocações feitas pelos seus autores; por outro, não se deve abandoná-lo de todo, cabendo ressignificálo no tempo-espaço das sociedades contemporâneas. Com efeito,

[...] a base do cenário do Manifesto não sofreu alterações radicais. 0 proletariado global nunca foi tão volumoso, nem nunca tão forte o imperativo da união dos trabalhadores de todo o mundo. Mas as barreiras a essa união são muito mais formidáveis do que o eram no contexto europeu já complicado de 1848. A força de trabalho se acha hoje bem mais dispersa em termos geográficos, mais heterogêneas 
em termos culturais, mais diversificada étnica e religiosamente, racialmente estratificada e linguisticamente fragmentada. Isso leva a uma radical diferenciação tanto das modalidades de resistência ao capitalismo como das definições de alternativas. E embora seja verdade que os meios de comunicação e as oportunidades de tradução tenham passado por grande aprimoramento, trata-se de algo que pouco significa para os cerca de 1 bilhão de trabalhadores que vivem com menos de um dólar por dia e se acham imersos em diferentes histórias culturais, literaturas e compreensões (em comparação com financistas internacionais e corporações transnacionais que usam o tempo inteiro as novas formas de comunicação). (HARVEY, 2004, p. 68)

O que, aliás, foi, paulatinamente, compreendido pela própria parcela da sociedade que se acha dentro do 1 bilhão de trabalhadores considerados nesta citação, buscando, deste modo, outras formas de resistência e luta. Neste âmbito, portanto, começou-se a se contestar a necessidade das vanguardas - presente em Marx e, principalmente, em Lenin - atuando, através dos partidos comunistas, junto às classes trabalhadoras a fim de levá-las à tão almejada e defendida consciência revolucionária.

Ideia que se contrapôs, ainda no início do século XX, às de intelectuais orgânicos como Rosa Luxemburgo e Antonio Gramsci, os quais confiavam na capacidade do povo de formar seus próprios intelectuais e, por conseguinte, respeitando sua própria dinâmica. Nesta perspectiva, buscando sua autonomia com relação à tutela das instituições acima referidas, os movimentos sociais começaram a libertar-se de tais influências, organizando-se de acordo com a própria dinâmica social.

A ideia de autonomia dos movimentos sociais passou a ser defendida, também, por lideranças locais que, na prática, se tornavam presidentes de Associações de Moradores, presidentes de Conselhos de Moradores, presidentes de Clubes de Mães, etc. nos seus respectivos territórios de existência. Diante desta lógica diferente de organização social - considerada como nova - estas práticas foram denominadas de "novos movimentos sociais", sendo estes, portanto, compreendidos como a segunda ideia reconhecida acerca da dinâmica social ora em discussão.

Essas novas práticas de movimentos sociais, sempre numa perspectiva de mudança para melhor, caracterizam-se, tal como já fora argumentado,

[...] por suas lutas para romper com seus esquemas populistas do passado, para a criação de formas comunitárias de participação direta das bases do nível da reflexão, da decisão e da execução, diminuindo ao mínimo a distância entre direção e base do movimento. Defendem sua autonomia frente ao Estado e Partidos, considerando a cidadania um direito do povo, numa situação de um capitalismo particularmente excludente. A defesa da autonomia não significa que o partido não poderá ser utilizado como um canal de encaminhamento das reivindicações dos movimentos sociais. [...] Essa nova prática, contudo, não se encontra isenta de ambiguidade, na medida em que frequentemente o líder do novo movimento social é igualmente um líder partidário. Por outro lado, isso tem trazido para os partidos a consciência sobre a necessidade do respeito à autonomia das instâncias (SCHERER-WARREN, 1987, p. 42).

Nota-se, nesta definição, que, diferente do que acontece nos nossos dias, o partido ainda era valorizado como uma instituição que contribuiria para a representação dos interesses sociais no âmbito do Estado. Ao mesmo tempo, a postura comum - a de caráter um tanto clientelista - de parte 
das lideranças foi vista, posteriormente, como algo não interessante, daí a procura pela coordenação ao invés do sistema de liderança presidido por alguém.

Um dos trabalhos mais lidos que fomentou a reflexão acerca do papel dos movimentos sociais na transformação social no início dos anos 1970 foi sem sombra de dúvidas, segundo Abreu (1994), a Questão Urbana, no qual o autor (CASTELLS, 1972) levantou a ideia de que a cidade deveria ser repensada e praticada como o espaço viabilizador da revolução.

Com base na contribuição teórica de Henri Lefèbvre e Louis Althusser, dizia Abreu (1994) que, muito além da contradição básica do capitalismo - entre trabalho e capital - dever-se-ia considerar já naquela época uma outra a qual seria mais pertinente no sentido da busca de um caminho plausível visando à revolução. E neste caso, segundo Castells (1972), haveria outras contradições que deveriam ser levadas em conta com a finalidade de formar e consolidar o que ele chamou de unidade de ruptura do capitalismo.

A cidade foi vista, então, por Castells, como o espaço mais provável à concretização da referida unidade de ruptura porque é neste espaço que as diversas contradições - a básica que também não deveria deixar de ser considerada e as relativas ao consumo coletivo em termos de obras e serviços urbanos - mais se acumulam no tempo, sob um processo nítido e dinâmico de urbanização do mundo.

Ademais, ainda para Castells, eram as contradições no âmbito do consumo coletivo que suscitariam com maior força, na cidade, o acontecer dos movimentos sociais urbanos. Mas, continuando o seu raciocínio, como tais práticas sociais não alcançariam a unidade de ruptura de maneira espontânea, necessitar-se-ia de algum estímulo externo, ou seja, de um partido político como uma vanguarda! - que estivesse efetivamente comprometido com as causas levantadas pelas referidas mobilizações.

Vale ressaltar, portanto, a importância que esta obra teve aqui no Brasil no momento em que se começou a apreender e compreender o surgimento dos novos movimentos sociais em torno da problemática urbana ligada à ausência ou à precariedade dos bens de consumo coletivo em diversos territórios vividos da cidade. Com efeito, vale ressaltar que,

No caso específico do Brasil, a difusão [desta] obra deu-se num momento muito especial [...]. Com efeito, ao coincidir com a fase de esgotamento do regime militar, [...] a Questão Urbana acabou se transformando em obra de apoio fundamental para todos aqueles que pretendiam estudar a cidade brasileira, já que aí passavam a ter lugar muitos dos movimentos sociais que Castells discutira em sua obra. E estes movimentos eram de vários matizes, e 'pipocavam' em todo lugar, especialmente nas periferias metropolitanas. Eram movimentos que reivindicavam água, luz, condução, escolas, saneamento, acesso à moradia... Eram movimentos que lutavam também pelo estabelecimento de uma nova forma de relação entre aqueles que habitavam a cidade e o Estado, que exigiam um maior grau de participação popular no processo de tomada de decisões. Eram, enfim, movimentos que ultrapassavam o caráter reivindicatório, pois acabavam por exigir um direito que havia sido negado por longo tempo à maior parte da população brasileira: o direito à cidadania (ABREU, 1994, p. $60)$. 
Compreendendo esta obra em sua época, decerto, ela abriu vários nortes na perspectiva de se valorizar outras experiências de ações em termos de mobilização social na cidade a exemplo daquelas referentes, por exemplo, aos movimentos de bairro os quais foram muito importantes para o processo de politização da questão urbana em cidades como a de Recife (CASTILHO, 2015).

Retomando a discussão dos movimentos sociais como "alavancas da mudança social" presente em sua obra mais recentemente, Castells (2013) recolocou alguns pontos escritos anteriormente a fim de atualizar, em certa medida, a sua definição com relação a estas práticas de organização e mobilização sociais.

Ao longo da história, os movimentos sociais são produtores de novos valores e objetivos em torno dos quais as instituições da sociedade se transformaram a fim de representar esses valores criando novas normas para organizar a vida social. Os movimentos sociais exercem o contrapoder, construindo-se, em primeiro lugar, mediante o processo de comunicação autônoma, livre do controle dos que detêm o poder institucional (CASTELLS, 2013, p. 14).

Continuando o seu raciocínio, nesta mesma citação, este mesmo autor começou a relacionar a dinâmica do acontecer histórico dos movimentos sociais com a utilização dos meios de comunicação, defendendo a tese de que

Como os meios de comunicação de massa são amplamente controlados por governos e empresas de mídia, na sociedade em rede [a atual] a autonomia de comunicação é basicamente construída nas redes da internet e nas plataformas de comunicação sem fio. As redes sociais digitais oferecem a possibilidade de deliberar sobre e coordenar as ações de forma amplamente desimpedida (CASTELLS, 2013, p. 14)

Muito embora, ainda para este mesmo autor, os movimentos sociais não possam prescindir do processo permanente de construção de um espaço público a fim de criar comunidades livres no âmbito do espaço geográfico, seja urbano seja rural.

E foi a utilização das novas tecnologias ligadas às redes sociais que possibilitou o desenvolvimento das condições necessárias para a difusão e descentralização dos movimentos sociais tal como tem acontecido nos nossos dias, quebrando as barreiras do isolamento e superando o medo de lutar.

Santos (2000), numa perspectiva mais complexa e ponderada do ponto de vista das suas possibilidades, também acreditava na utilização da dimensão das técnicas como fator importante no processo de mudança social. Mas, isso aconteceria na medida em que fossem, contraditoriamente, utilizadas para fins preponderantemente humanos. Nesse sentido, dizia ele que:

Agora que estamos descobrindo o sentido de nossa presença no planeta, pode-se dizer que uma história universal verdadeiramente humana está, finalmente, começando. A mesma materialidade atualmente utilizada para construir um mundo confuso e perverso, pode vir a ser uma condição da construção de um mundo mais humano. [...] A grande mutação tecnológica é dada com a emergência das técnicas da informação, as quais - ao contrário das técnicas das máquinas - são constitucionalmente divisíveis, flexíveis e dóceis, adaptáveis a todos os meios e culturas, ainda que seu uso perverso atual seja subordinado aos interesses dos grandes capitais. Mas, quando sua utilização 
for democratizada, essas técnicas doces estarão ao serviço do homem. (SANTOS, 2000, p. 174)

Com efeito, quantos moradores - pobres - das cidades e quantos grupos sociais - indígenas, ribeirinhos, quilombolas, sem-terra, sem-teto, etc. - não têm utilizado as novas tecnologias para filmar as condições precárias de vida, de trabalho e de ameaças à sua expulsão dos próprios territórios em que vivem? E isto a fim de contar a sua história, denunciar as desigualdades e injustiças sofridas, discutir seus problemas e mobilizar-se para a realização de protestos visando à mudança da sua condição de existência.

Enfim, hoje, numa prática mais difusa, formaram-se movimentos sociais numa perspectiva múltipla e descentralizada, os quais poderiam ser compreendidos também como novos movimentos sociais. Mas, acontecendo no âmbito de uma lógica diferente das que guiaram as atividades inerentes aos tipos de movimentos sociais anteriormente citados.

Estes últimos constituem o resultado de ações que não se acham sob a tutela das instituições referidas acima e que não possuem lideranças tradicionais a exemplo daqueles que tinham seus presidentes. Eles atuam, ao contrário, de maneira mais descentralizada e buscam resolver suas questões por meio de discussões e debates norteados por "Coordenações" compostas por membros Coordenadores - saídos dos próprios territórios a partir dos quais os movimentos se formam e articulados cada vez mais pela utilização das novas tecnologias de informação e conhecimento ao alcance de todos e todas.

Apesar de ser algo difícil de ser apreendido e definido mormente pela sua viscosidade e plasticidade (CASTILHO, 2013), parece-nos, à primeira vista, depois de tudo o que resgatamos até o presente momento neste exercício teórico-prático de síntese, que a definição abaixo abarca a complexidade dos movimentos sociais como uma dinâmica social permanente, caminhando em algum sentido, nos diversos territórios do seu acontecer histórico.

Movimentos sociais são ações sociopolíticas construídas por atores sociais coletivos pertencentes a diferentes classes e camadas sociais, articuladas em certos cenários da conjuntura socioeconômica e política de um país, criando um campo político de força social na sociedade civil. As ações se estruturam a partir de repertórios criados sobre temas e problemas em conflitos, litígios e disputas vivenciados pelo grupo na sociedade. As ações desenvolvem um processo social e político-social que cria uma identidade coletiva para o movimento, a partir dos interesses em comum. Esta identidade é amalgamada pela força do princípio da solidariedade e construída a partir da base referencial de valores culturais e políticos compartilhados pelo grupo, em espaços coletivos não-institucionalizados. Os movimentos geram uma série de inovações nas esferas pública (estatal e não-estatal) e privada; participam direta ou indiretamente da luta política de um país, e contribuem para o desenvolvimento e a transformação da sociedade civil e política. [...] Os movimentos participam portanto da mudança social histórica de um país e o caráter das transformações geradas poderá ser tanto progressista como conservador ou reacionário, dependendo das forças sociopolíticas a que estão articulados, em suas densas redes; e dos projetos políticos que constroem em suas ações. Eles têm como base de suporte entidades e organizações da sociedade civil e política, com agendas de atuação construídas ao 
redor de demandas socioeconômicas ou político-culturais que abrangem as problemáticas conflituosas da sociedade onde atuam. (GOHN, 1997, pp. 251-252)

Em sendo assim, os movimentos sociais constituem a própria sociedade em movimento no mundo, no e a partir dos seus territórios de existência, como uma totalidade social complexa que se move permanentemente em alguma direção. E o diferente em termos de sociedade acontecerá em função da natureza das estratégias políticas dos seus movimentos.

Porém, ao mesmo tempo, não podemos deixar de compreendê-los no âmbito dos seus respectivos contextos ambientais - ou seja, na trama de uma totalidade complexa formada pelas interrelações entre o social, político e cultural - específicos a cada território. Em assim sendo, cada território possui suas formas de pensar e atuar no mundo, suas territorialidades; logo, cada território possui sua forma específica de fazer os seus movimentos sociais, buscando sempre elaborar e implementar as estratégias condizentes com a sua própria realidade cotidiana. Porém, tais especificidades não podem impedir a necessária articulação global que deve ser feita.

\section{BUSCA DE ESTRATÉGIAS POLÍTICAS EFICAZES}

A articulação social, sob a liderança de um líder carismático, condutor das classes sociais subalternas - constituídas, sobretudo, de operários e camponeses - em torno dos problemas enfrentados no âmbito das suas condições precárias de existência, constituía uma alternativa visando à formação de um movimento revolucionário para tomar o Estado e, a partir do uso desta instituição social-política, transformar a sociedade.

Entretanto, esta perspectiva de tomada do Poder, do Estado, definida por Gramsci (1978) como guerra de movimento, não era suficiente para a concretização do objetivo da transformação social, sobretudo nos lugares em que o capitalismo se fazia forte tanto física como simbolicamente.

Contra esta perspectiva, este mesmo autor, criticando a ideia de vanguarda revolucionária defendida por Lenin - argumentou que, principalmente no contexto de uma sociedade capitalista consolidada, fazia-se importante, pela sua plausibilidade, a ideia de guerra de posição. Através desta ideia, dizia ele que a sociedade deveria, em países, por exemplo, como a Itália, ocupar, primeiramente, as várias posições no interior dos aparelhos do Estado de maneira a, pelo consenso, convencer, ao nível também do simbólico, a sociedade da necessidade de mudança.

Isto porque, para Gramsci (1975), o Estado burguês não se sustentava apenas com base na dominação e repressão, tal como pensavam os marxistas ortodoxos, em particular; mas, ao mesmo tempo, no consenso, visto que em tais sociedades a hegemonia - direção intelectual e moral das classes hegemônicas (a, então, burguesia) - era exercida por meio da sociedade civil. Em assim sendo, indagamos de que adiantaria, por exemplo, tomar o Estado e deixar as relações sociais de produção seguirem a mesma racionalidade técnico-instrumental que norteava a lógica capitalista anterior. 
E, ao mesmo tempo, dizia ele que cada nação possui especificidades - diríamos históricoterritoriais - as quais, por sua vez, exigiria outras estratégias diferentes de ações das que haviam sido empregadas durante a Revolução Russa de 1917, segundo suas próprias forças produtivas e suas próprias relações conflitivas.

Parece-nos que, principalmente em territórios de exacerbada precariedade em termos de condições existenciais de vida como muitos no Brasil, com uma sociedade civil fraca ou inexistente, portanto dependentes de lideranças, os movimentos sociais também foram organizados de maneira ortodoxa. Isto quer dizer que, a sociedade deveria organizar-se em torno de lideranças vanguardistas que guiariam as atividades realizadas na direção da revolução. 0 que se imaginava acontecer pela tomada do Estado, sem considerar a ponderação feita por Gramsci.

No que diz respeito aos novos movimentos sociais, estes buscaram, em princípio, certa autonomia com relação às lideranças vanguardistas tradicionais. Muito embora, na prática, o que aconteceu foi a substituição das vanguardas tradicionais pela dos presidentes de Associações de Moradores, Conselhos de Moradores, Clubes de Mães, etc. sobretudo pela forte dependência dos participantes com relação a tais lideranças.

A preocupação principal destes atores não era diretamente com a realização da revolução tal como buscavam os movimentos sociais tradicionais, tomando o Estado pela guerra de movimento; mas, com a resolução imediata das condições precárias de existência inerentes ao cotidiano dos moradores que a eles se juntavam.

Isso acontecia, primeiramente, pela reivindicação dos chamados bens de consumo coletivo: habitação, obras de infraestrutura urbana (saneamento, pavimentação, drenagem, etc.), transporte público, educação, saúde, dentre tantos outros que, no geral dependem das condições inerentes ao sítio geográfico-social das cidades.

Esse caráter baseado notadamente em reivindicações por direitos, para as lideranças e os intelectuais tradicionais, não fazia de tais ações movimentos sociais verdadeiros, dado que estes só deveriam referir-se, em princípio, àqueles que lutavam pela revolução, seguindo o discurso único da esquerda ortodoxa.

Contudo, temos que considerar que a mobilização pelo acesso aos bens de consumo coletivo como direitos sociais, também constitui parte do processo global de luta pelo direito à cidade. A propósito, como disse Santos (1987), valorizando a luta pela conquista de tais bens no seu território, visando a ser mais, este processo traduzir-se-ia no fato de que

Cada homem vale pelo lugar onde está: o seu valor como produtor, consumidor, cidadão, depende da sua localização no território. Seu valor vai mudando, incessantemente, para melhor ou para pior, em função das diferenças de acessibilidade (tempo, frequência, preço), independentes de sua própria condição. Pessoas com as mesmas virtualidades, a mesma formação, até mesmo o mesmo salário têm valor diferente segundo o lugar em que vivem: as oportunidades não são as mesmas. Por isso, a possibilidade de ser mais ou menos cidadão depende, em larga 
proporção, do ponto do território de onde se está. Enquanto um lugar vem a ser condição de sua pobreza, um outro lugar poderia, no mesmo momento histórico, facilitar o acesso àqueles bens e serviços que lhes são teoricamente, mas que, de fato, lhe faltam (SANTOS, 1987, p. 81).

Em assim sendo, acreditamos que o povo possui a consciência de que só poderá conquistar uma sociedade profundamente diferente depois de ser mais, para o que, aliás, deveria, antes de tudo, fazer do seu território um espaço do cidadão, superando a sua condição de não-cidadania (SANTOS, 1987) ou de subcidadania (2015), a fim de se tornar um lugar forte (SANTOS, 1997). Trata-se, enfim, de uma condição efetiva para negociar - com o Estado - o que for mais coerente com as suas reais necessidades.

Quanto à grande parte dos movimentos sociais que vêm acontecendo nos nossos dias, eles estão organizados numa perspectiva mais difusa e descentralizada no âmbito de redes de ações, buscando liberarem-se de todo tipo de tutela e, muitas vezes, negando as instituições sociais tradicionais. 0 que, algumas vezes, os aproxima de tendências anarquistas tais como as dos chamados "coletivos", mas, por outro lado, também não deixa de recolocar questões relevantes.

Ressaltamos, assim, que a perspectiva dos movimentos sociais em rede acha-se mais adequada para o mundo de hoje, na medida em que nos permite aproximar da complexidade no que tange às suas diversas ações contextualizadas na totalidade histórico-territorial do processo social.

Pode-se afirmar que há evidências empíricas de que [...] os movimentos sociais e seus mediadores passaram por transformações que vão da valorização das organizações de base (grassroots organizations), para mais recentemente o reconhecimento crescente da importância das articulações, intercâmbios e formação de redes, temáticas e organizacionais (network organizations). Entretanto, tendo-se em vista que a realidade dos movimentos sociais é multifacetária, sabe-se também que será cenário para uma diversidade de investigações e perspectivas analíticas. Analisar este cenário em termos de 'redes de movimentos' é, pois, uma opção. A ideia de 'rede' implica pensar, desde um ponto de vista epistemológico, na possibilidade de 'integração de diversidade' [...]. Distingue-se da ideia de 'unicidade' totalizadora, comum em interpretações do marxismo positivista acerca da necessidade de articulações das lutas sociais. A análise em termos de 'redes de movimentos' implica buscar as formas de articulação entre o local e do global, entre o particular e o universal, entre o uno e o diverso, nas interconexões das identidades dos atores com o pluralismo (SCHERERWARREN, 1996, p. 9-10).

Com efeito, no conjunto dos movimentos ora em questão, existe uma diversidade enorme em termos de tipos, estilos, maneira de pensar e atuar, etc.; o que, por outro lado, tem dificultado muito a sua apreensão científica e, por sua vez, o seu entendimento, tornando sua apreensão ainda mais difícil cientificamente.

Para nós, esta terceira expressão dos movimentos sociais é interessante na medida em que vem fazendo uma crítica clara e profunda das instituições políticas e sociais que se dizem nossas representantes, o que, aliás, é algo interessante do anarquismo ${ }^{4}$. Muito embora não estejamos de

\footnotetext{
4 O anarquismo constitui uma "Doutrina segundo a qual o indivíduo é a única realidade, que deve ser absolutamente livre e que qualquer restrição que lhe seja imposta é ilegítima; daí a ilegitimidade do Estado". Para Mikhail Bakunin, um anarquista
} 
acordo com a negação do Estado e da sua capacidade de contribuir para algo diferente em termos de sociedade.

Concomitantemente, estes tipos de movimentos estão dando voz à grande diversidade que constitui o conjunto das forças sociais do nosso país, suscitando a necessidade de se revalorizar todos os indivíduos, todas as pessoas e todos os grupos sociais 5 : os dos sem-terra, os dos sem-teto, os das mulheres, os dos homossexuais, os dos transexuais, os dos ribeirinhos, os dos negros, os dos índios e assim por diante bem como as suas ações.

Tais movimentos desejam, na realidade, contribuir não somente para o aumento da autoconsciência dos cidadãos e das cidadãs; mas, ao mesmo tempo, para convocar a sociedade como um todo a sair da sua zona de conforto, encorajando-a a participar das suas atividades - nos diversos espaços públicos e concretos da sua existência - com vistas à recuperação da confiança com relação à sua própria capacidade de resistir a tudo o que lhe oprime e de lutar pelo que deseja.

No âmbito desta forma diferente de atuar na sociedade, algumas falas dos intelectuais 6 , mormente buscando valorizar a própria dinâmica social existente, aproximaram-se do que havia pensado Foucault (1990), no que diz respeito, por exemplo, ao papel dos intelectuais na sociedade contemporânea.

O intelectual não tem mais que desempenhar o papel daquele que dá conselhos. Cabe àqueles que se batem e se debatem encontrar, eles mesmos, o projeto, as táticas, os alvos de que necessitam. 0 que o intelectual pode fazer é fornecer os instrumentos de análise, e é este hoje, essencialmente, o papel [...]. Trata-se, com efeito, de ter do presente uma percepção densa, de longo alcance, que permita localizar onde estão os pontos frágeis, onde estão os pontos fortes, a que estão ligados os poderes - segundo uma organização que já tem cento e cinquenta anos - onde eles se implantaram. Em outros termos, fazer um sumário topográfico e geológico da batalha... Eis aí o papel do intelectual. Mas de maneira alguma dizer: eis o que vocês devem fazer! (FOUCAULT, 1990, p. 151).

russo, dever-se-ia " [...] destruir todas as leis, instituições e crenças existentes. A tese anarquista da contraposição nítida e radical entre todas as ordens políticas e sociais existentes, consideradas como o próprio mal, e a nova ordem libertária futura, considerada como o bem total for reapresentada por [diversos intelectuais]. As formas de anarquismo e de neoanarquismo inspiraram até mesmo os filósofos pós-estruturalistas (Deleuze, Guattari, Foucault etc.), que, sob a influência de Nietzsche, teorizaram sobre a existência de um universo sem ordens fixas e razões centralizadoras, no qual as 'diferenças' pudessem agir de maneira livre e transgressiva..." (ABBAGNANO, 2014, p. 62).

5 Apesar de se ter dito, por um lado, que as categorias de "sujeito popular" ou de "ator social" teriam substituído às de "classe social" e de que, por outro, as de "movimento popular" e de "movimento social" teriam substituído a de "luta de classes", sobretudo em função da crítica à ideia da revolução pela tomada do Estado; acreditamos que, na verdade, as referidas categorias acham-se relacionadas ao processo histórico global da luta de classes. E isto ainda que, nos tempos de hoje, a dimensão cultural vinculada ao cotidiano das pessoas envolvidas tenha ocupado espaço cada vez maior no âmbito dos movimentos sociais.

${ }^{6}$ Para nós, todos os homens e todas as mulheres são intelectuais, muito embora nem todos os homens e todas as mulheres tenham cumprido com os seus respectivos papeis de intelectuais. Intelectuais seriam, portanto, aqueles e aquelas que "[...] desenvolve uma atividade intelectual qualquer, ou seja, é um filósofo, um artista, um homem de gosto, participa de uma concepção do mundo, possui uma linha consciente de conduta moral, contribui assim para manter ou para modificar uma concepção de mundo, isto é, para promover novas maneiras de pensar. [...] O novo modo de ser do novo intelectual não pode mais consistir na eloquência, motor exterior e momentâneo dos afetos e das paixões, mas num imiscuir-se ativamente na vida prática, como construtor, organizador, 'persuasor permanente', já que não apenas orador puro - e superior, todavia, ao espírito matemático abstrato; da técnica-trabalho, eleva-se à técnica-ciência e à concepção humanista histórica, sem a qual se permanece 'especialista' e não se chega a 'dirigente' (especialista mais político)” (GRAMSCI, 1989, p. 7-8). 
Todavia, estamos percebendo que, apesar dos avanços atinentes a tais experiências de movimentos sociais, há dificuldades no que diz respeito à necessidade do encontro entre as suas ações no sentido de, com base em sua reconhecida experiência acumulada no curso da história urbana, se buscar algo em termos de articulação em torno de algum projeto mais global. Com efeito, vale ressaltar que

Os grandes movimentos que há vinte anos vêm sacudindo as sociedades ocidentais jovens, mulheres, minorias étnicas e culturais, ecológicas - certamente tiveram (e conservam potencialmente) uma importância considerável sob todos os pontos de vista, e seria inconsequente acreditar que seu papel esteja terminado. Mas, atualmente, seu refluxo os deixa numa situação de grupos não somente minoritários, mas fragmentados e setoriais, incapazes de articular seus objetivos e seus meios em termos universais ao mesmo tempo objetivamente pertinentes e mobilizadores. (CASTORIADIS, 2002, p. 16)

O que, para este mesmo autor, estaria relacionado ao fato de que a sociedade contemporânea encontra-se cada vez mais fragmentada e controlada por lobbies de diversos tipos cujas ações conseguem impedir o florescimento de ações políticas efetivamente diferentes em termos de práticas sociais, entravando-as com a finalidade de continuar satisfazendo apenas os interesses hegemônicos.

Não se está aqui voltando no tempo através da defesa de uma "ideia fora do tempo-espaço" segundo a qual se deveria articular em torno de um só objetivo - o da revolução puxada por uma vanguarda revolucionária - que não teria mais sentido no mundo de hoje.

Mas de, procurar fazer a síntese da qual se necessita, a fim de prover os movimentos sociais dos instrumentos teóricos e metodológicos necessários visando à reflexão sobre o seu ser-existir na sociedade contemporânea. Com efeito, vale ressaltar que, de posse de tais instrumentos,

[...] os movimentos sociais e pensamentos que tentam entender o contemporâneo já não podem se furtar ao pensar da falácia da democracia liberal como o último sistema possível, já que o mesmo sempre dá sinais claros de esgotamentos e contradições profundas. Por outro lado, esses mesmos movimentos sociais precisam se reinventar, equalizando suas bandeiras sob um leque mais ampliado, visando garantir uma práxis realmente transformadora, e não apenas cuidar de apagar os incêndios que surgem de quando em quando neste sistema que é naturalmente excludente. E para isso, é preciso não só expor as contradições do sistema hegemônico vigente, mas estar conectado às novas formas de interação social como a Internet, fazendo deste espaço de disputa política, equalização de bandeiras dos movimentos sociais anti-sistêmicos e espaço privilegiado para o desejo e o debate sobre o pensamento utópico de que outro mundo completamente diferente é possível. (MATOS, 2015, p. 61)

Estamos defendendo a necessidade de se buscar, num aprendizado permanente no âmbito do tempo-espaço desconhecido, os diversos atores nas diversas práticas do seu acontecer históricogeográfico a fim de que, no efetivo diálogo entre eles, se possa discutir e decidir sobre um projeto para todos e todas no mundo atual.

Sem o que se corre o grande risco de exacerbar ainda mais a fragmentação social-territorial contemporânea na qual vivemos, fragmentando ainda mais as possibilidades de mudança contidas na própria realidade existencial dos homens e das mulheres. 
A lição é clara: enquanto nós arquitetos rebeldes não conhecermos a coragem de nossa mente e estivermos preparados para dar um mergulho igualmente especulativo em algum desconhecido, também nós continuaremos a ser objetos da geografia histórica (como abelhas operárias) em vez de sujeitos ativos que levem conscientemente ao limite as possibilidades humanas. Aquilo a que Marx deu o nome de 'movimento real' que vai abolir 'o estado de coisas atual' está sempre por ser feito e por ser apropriado. Esse é o único sentido que pode ter adquirido a coragem de nossa mente. (HARVEY, 2004, p. 334)

A busca da concretização do direito à cidade é, na verdade, o objetivo dos movimentos sociais em geral, não obstante a diversidade em termos de tipos, formas, estratégias e cultura dos movimentos ora em apreço. Destarte, as metas de tais ações vão muito além da obtenção de melhores condições de vida mediante o acesso a bens de consumo coletivo, mas, concomitantemente como produtores da história dos homens e das mulheres no seu mundo, questionando a realidade existente e buscando superá-la pelo que desejam.

Isto porque o direito à cidade é muito mais do que, simplesmente, ter acesso ao conjunto dos bens de consumo coletivo e de obras de infraestrutura espacial, mas, concomitantemente, o direito de participar do processo de produção do espaço urbano como uma possibilidade interminavelmente aberta (LEFEBVRE, 1968) e, por conseguinte, de mudar a nós mesmos ao mudar a cidade (HARVEY, 2012). Nessa perspectiva, o espaço urbano foi considerado como um "livro sempre aberto" (LEFBVRE, 1968) sujeito a renovações permanentes. O que, muitas vezes, nos impulsiona a buscar negociar com o Estado, pressionando-o a fazer valer os nossos interesses.

\section{MOVIMENTOS SOCIAIS E ESTADO: UMA RELAÇÃO SECULAR “DE AMOR" E "DE ÓDIO" AINDA NÃO RESOLVIDA, MAS NECESSÁRIA...}

Não se nega o papel ambíguo do Estado na sociedade, razão pela qual há, sem meios termos, os que o odeiam e os que o amam, o que aproxima os primeiros da ideia do Estado como uma espécie de comitê executivo da burguesia (MARX, 1987) e os segundos da ideia do Estado como um mal necessário (MARX, 1987).

Esta polêmica não acontece à toa, mas é proveniente da própria relação histórica estabelecida entre o Estado e a sociedade no âmbito dos conflitos inerentes à luta de classes durante a história da humanidade, na perspectiva de se buscar alguma solução.

A história mostra que os processos revolucionários, segundo Chauí (1999), tenderam a derrubar o poder do Estado porque as suas lideranças o identificaram como cúmplice da manutenção dos interesses das classes hegemônicas, responsável, portanto, pelas desigualdades e injustiças territoriais. E isto corroborando que a ideia de que a

[...] percepção de injustiças sociais [nos territórios vividos] leva às ações políticas. Uma revolução pode começar como luta social que desemboca na luta política contra o poder ou pode começar como luta política que desemboca na luta por uma outra 
sociedade. Eis por que, em todas as revoluções burguesas, vemos sempre acontecer o mesmo processo: a burguesia estimula a participação popular, porque precisa que a sociedade toda lute contra o poder existente; conseguida a mudança política [...], a burguesia considera a revolução terminada: as classes populares porém a prosseguem, pois aspiram ao poder democrático e desejam mudanças sociais; a burguesia vitoriosa passa a reprimir as classes populares revolucionárias, desarma o povo que ela própria armara, prende, tortura e mata os chefes populares e encerra, pela força, o processo revolucionário, garantindo, com o liberalismo, a separação entre Estado e sociedade (CHAUÍ, 1999, p. 405).

É o que - com ou sem revolução - continua a acontecer nos dias de hoje, no momento em que, por exemplo, em contextos de retrocessos históricos, vemo-nos, mais uma vez, diante de diversas ações, tanto nos meios urbanos quanto rurais, de desterritorialização de homens e mulheres de baixa renda, pobres, e destruição da natureza para atender os imperativos da lógica da racionalidade técnico-instrumental capitalista, visando à geração de valores puramente econômicos.

E tais processos nefastos à existência saudável dos homens e das mulheres, que acabamos de colocar no parágrafo anterior, ocorrem de maneira ainda mais forte quando os movimentos sociais acham-se, em certa medida, fracos e/ou calados. De acordo com Marx \& Engels (1987),

A cada etapa da evolução percorrida pela burguesia correspondia um progresso político. Classe oprimida pelo despotismo feudal, associação armada administrando-se a si própria na comuna; em seguida, república urbana independente, logo terceiro estado, tributário da monarquia; depois, durante o período manufatureiro, contrapeso da nobreza na monarquia feudal ou absoluta, pedra angular das grandes monarquias, a burguesia, desse o estabelecimento da grande indústria e do mercado mundial, conquistou, finalmente, a soberania política, exclusiva do Estado representativo moderno. O Governo moderno não é senão um comitê para gerir os negócios comuns de toda a classe burguesa (destaque nosso). (ENGELS, 1987, p. 29-30).

Com efeito, no Brasil, sobretudo após os anos 1930, segundo Araújo (2000), o que de fato tem caracterizado o seu Estado foi o seu aspecto desenvolvimentista-conservador-autoritário, e não o de um Estado do bem-estar social, voltando-se sobretudo para o crescimento econômico de acordo com os interesses das classes sociais hegemônicas.

Daí a permanência dos problemas sociais decorrentes das desigualdades e injustiças territoriais ao longo de todo o processo de formação territorial do país, não obstante o fato de que, em alguns momentos do tempo histórico, houve avanços sociais, ainda que, logo em seguida, os movimentos sociais tenham sido reprimidos e criminalizados. Tal como argumentara Ribeiro (2015),

[...] as elites dirigentes, primeiro lusitanas, depois luso-brasileiras e, afinal, brasileiras, viveram sempre e vivem ainda sob o pavor pânico do alçamento das classes oprimidas. Boa expressão desse pavor pânico é a brutalidade repressiva contra qualquer insurgência e a predisposição autoritária do poder central, que não admite qualquer alteração da ordem vigente (RIBEIRO, 2015, P. 20).

Outra herança cultural perversa do processo de formação do povo brasileiro ressaltada por Ribeiro (2015, p. 21) reside no fato de que as classes hegemônicas brasileiras, isto é, as privilegiadas sempre buscaram isolarem-se "[...] numa barreira de indiferença para com a sina dos pobres, cuja miséria repugnante procuram ignorar ou ocultar numa espécie de miopia social, que perpetua a 
alternidade". 0 que provavelmente se deve ao medo de que o povo não desperte para o fato de que a formação territorial brasileira foi na verdade uma máquina de "gastar gente" a qual, quando usada até à sua exaustão, é descartada como lixo. Daí, "O grande desafio que o Brasil enfrenta é alcançar a necessária lucidez para concatenar [suas] energias e orientá-las politicamente, com clara consciência dos riscos de retrocessos e das possibilidades de liberação que elas ensejam". E os movimentos sociais constituem de fato canais relevantes, pensamos, mais eficazes para alcançar a sua liberação.

Contudo, mediante uma perspectiva heurística, são as desigualdades e injustiças supracitadas, percebidas pela sociedade, que, de uma certa feita, suscitam o acontecer histórico dos movimentos sociais que se formam visando à conquista do lugar dos seus ativistas na sociedade, fazendo-nos reconhecer que

O Brasil tem grande resistência ao neoliberalismo. Observemos a dificuldade para se fazer o ajuste no Brasil. [...] Se há a crise da CUT, a crise da CONTAG, existem também o Movimento dos Sem-Terra e o Movimento dos Sem-Teto explodindo. Esses movimentos temáticos [ao lado dos outros já mencionados antes neste artigo] são novas formas de luta no mundo inteiro. Estão tão vivos, organizados e presentes [...] que não estão deixando o movimento sindical morrer. Nós é que não conseguimos, ainda, operar com os dois, porque estávamos acostumados aos focos tradicionais de mediação. Temos o Movimento Nacional de Luta pela Moradia e o Movimento de Luta dos Atingidos por Barragens. 0 país está cheio desses organismos, que são locais, mas têm articulação nacional. Isto é descentralização coordenada. [...] Um dos novos papéis do Estado nacional é coordenar. [...] Quando não há espaço de negociação, devemos contestar para abrir este espaço. (ARAÚJO, 2000, p. 278-279)

Se, por um lado, existe este "Brasil que não se cala", colocado por Araújo (2000); por outro, sempre ocorrem - e ocorrerão - tentativas de, retornando ao que disse Ribeiro anteriormente, deixálo sem voz, tentando negá-lo e/ou mesmo criminalizando as suas práticas sociais. 0 que ocorre sobretudo pelo medo que as classes hegemônicas têm tido historicamente deste outro Brasil em potencial.

Contudo, nos anos 1980, diversos moradores dos territórios vividos tiveram seu direito de permanecer no espaço urbano reconhecido pela legislação municipal (Zonas Especiais de Interesse Social-ZEIS), bem como a institucionalização de um fórum específico para discutirem os seus problemas (Plano de Regularização das Zonas Especiais de Interesse Social-PREZEIS); posteriormente, nos anos 2000, moradores das cidades mobilizaram-se a fim de lutar contra as ameaças de expulsão dos seus territórios em face dos interesses ligados a projetos urbanísticos, muitos dos quais de caráter higienista-gentrificador; e viu-se, durante a experiência de quase dezesseis anos do governo do Partido dos Trabalhadores no Brasil, que houve um processo significativo de concretização de conquistas sociais através da implementação de um conjunto de políticas públicas voltadas para as classes subalternas.

Se, por um lado, tais conquistas ocorreram, sem sombra de dúvidas, em função da capacidade de negociação dos movimentos sociais com o Estando; por outro, devemos reconhecer que não há 
Estado que se omita diante de tal força social, exceto quando se está sob regime efetivamente autoritário.

Isto ocorre porque não aceitamos a ideia de que o Estado seja apenas um bloco monolítico em que todo o seu pessoal pensa e atua do mesmo modo, tal como nos alertaram, aliás, Gramsci (1971) e Poulanzas (1978). Mas que, como uma totalidade complexa, existem possibilidades de que esta instituição possa ser usada para fins outros que o da mera manutenção somente dos interesses das classes hegemônicas.

Trazendo esta questão para o debate contemporâneo de uma maneira mais prática, Bourdieu (1998) levantou a ideia de que o conjunto, por exemplo, dos trabalhadores sociais - assistentes sociais, educadores, magistrados e também, cada vez mais, docentes e professores primários - sofre com as condições precárias de existência das pessoas. Em sendo assim, estes trabalhadores constituem o que ele mesmo chamou de "mão esquerda do Estado". Na verdade, estes termos referem-se ao

[...] conjunto dos agentes dos ministérios ditos 'gastadores', que são o vestígio, no seio do Estado, das lutas sociais do passado. Eles se opõem ao Estado da mão direita, aos burocratas do ministério das Finanças, dos bancos públicos ou privados e dos gabinetes ministeriais. Muitos movimentos sociais a que assistimos (e assistiremos) exprimem a revolta da pequena nobreza contra a grande nobreza do Estado (BOURDIEU, 1998, p 10).

Portanto, o Estado possui rugosidades que podem e devem ser acionadas também pelas classes sociais subalternas, com vistas a atender os seus interesses e desejos, bastando para isto pressioná-lo. O que, aliás, já aconteceu no curso da história de qualquer território e dinâmica político-social, tal como visto quando citamos as experiências de conquistas sociais acima ocorridas em Recife; cidade que constitui, dentre tantas outras no mundo, um grande laboratório neste sentido.

Diante, então, do que acabamos de colocar nesta seção, há possibilidades de se concretizar relações dialógicas entre sociedade e Estado, desde que se tenham movimentos sociais fortes para fazer reivindicações e pressões na busca de negociar o que for necessário e interessante para os seus territórios, reforçando suas territorialidades.

Voltamo-nos, assim, à primazia da política, a qual conduz novamente a outro tema de fundamental relevância para os nossos dias, segundo o qual, sem dogmatismos de nenhuma espécie, nota-se que

[...] a teorização marxista do Estado mais e mais a postura segundo a qual a luta política para a transição ao socialismo tem de ser essencialmente democrática, no sentido de combinar uma expansão das lutas parlamentares e eleitorais com os movimentos sociais, o controle operário e outras formas de democracia direta. A ampliação da democracia em novas formas e, através delas, a ruptura com a lógica das relações sociais capitalistas constituem uma mudança dramática da estratégia marxista-leninista tradicional da 'falência do Estado' e, uma vez mais, refletem a realidade da história do pós-guerra. A 'descoberta' de Gramsci, o ataque ao estruturalismo e a reformulação da luta de classes representam um novo entendimento entre os marxistas, das limitações das teorias políticas deterministas para uma mudança radical (CARNOY, 1988, p. 17). 
É verdade que, para se fazer a revisão teórica e metodológica proposta acima, é de fundamental importância que exista um Estado sensível às demandas procedentes das outras classes sociais - as que não são ouvidas e contempladas pelos interesses hegemônicos - facilitando a negociação anteriormente citada.

Porém, quando suficientemente fortes, os movimentos sociais continuam a conseguir conquistas a exemplo das que se concretizaram, ainda durante o regime militar, nos anos 1970 e 1980: reconhecimento dos movimentos sociais, acesso a bens de consumo coletivo, experiências de participação na gestão pública, a Constituição da República Federativa do Brasil conhecida como "constituição cidadã", etc.

Portanto, faz-se necessário fortalecer-se para fazer com que o Estado use a sua "mão esquerda", não somente visando à conquista do Bem-Estar social, mas, simultaneamente, do BemViver no espaço geográfico.

\section{CONSIDERAÇÕES FINAIS}

Depois de ter feito uma tentativa de síntese acerca das principais correntes conceituais e práticas dos movimentos sociais ora considerados, os quais coexistem hoje na sociedade brasileira, a partir do conhecimento sobre as ações ocorridas em Recife, faz-se necessário ainda considerar em que medida tais correntes podem ser ressignificadas na busca de uma prática social voltada, efetivamente, à transformação social.

Está claro que, como vimos, os movimentos sociais constituem mesmo "alavancas da mudança social" os quais, por sua vez, têm sido definidos como forças revolucionárias, sobretudo pelas tendências mais à esquerda.

Porém, o que seria de fato uma revolução? Será que seria possível a concretização de um mesmo discurso - único - revolucionário em todos os lugares do Planeta? Será que devemos abandonar de todo as ideias revolucionárias ou ressignificá-las no tempo-espaço atual? Desse modo, o que seria hoje uma ação revolucionária? Isso, notadamente, pela relevância, ainda, destas questões.

Classicamente, as experiências de revolução, na verdade, acabaram atendendo preponderantemente aos interesses das classes sociais mais fortes economicamente, as quais faziam parte das chamadas forças revolucionárias. A este respeito, segundo Chauí (1999), complementando a citação feita desta mesma autora, na seção anterior deste artigo, ressaltamos que

[...] nas três revoluções [Revolução Inglese de 1644, Revolução Norte-Americana de 1776 e Francesa de 1789], a burguesia pretendeu e conseguiu derrotar a realeza e a nobreza, passou a dominar o Estado e julgou com isso terminada a tarefa das mudanças, enquanto as classes populares, que participaram daquela vitória, desejavam muito mais: desejavam instituir uma sociedade inteiramente nova, justa, livre e feliz (CHAUÍ, 1999, p. 404). 
Nessa perspectiva ações revolucionárias constituem práticas sociais, efetivamente, voltadas para mudar a sociedade, razão pela qual não se pode abandonar este conceito, sobretudo, para territórios em que, não havendo a cidadania, existem classes sociais vivendo sob precárias condições de existência.

Ao mesmo tempo, pensamos que, em vez de negar as experiências que tentaram, anteriormente, fazer uma revolução radical, temos que resgatá-las ao nível do pensamento e da reflexão para somar às existentes atualmente, especulando sobre o porquê da sua não realização. 0 que, talvez, tenha acontecido devido à visão simplista dos "revolucionários" a qual se limitou à tomada do Estado, ao mesmo tempo não contextualizando suas ideias e ações no tempo-espaço.

Temos, então, que recuperar as experiências mais significativas - no pensar e atuar - acerca dos movimentos sociais, ressignificando-as e revalorizando-as, no âmbito de uma perspectiva de síntese teórico-prática - próximo, como já o dissemos antes, de uma filosofia da praxis -, visando à retomada das lutas para a construção do espaço do cidadão pela conquista do direito à cidade. 0 que, porém, deve acontecer com os pés no chão.

Destarte, mesmo sabendo da dificuldade de se chegar a concretizar uma sociedade radicalmente diferente da existente, existe, porém, possibilidades de pelo menos se conquistar direitos rumo a uma situação próxima do que se imagina em termos de territórios como lugares fortes em que o direito à cidade seja concretizado e, por sua vez, o espaço do cidadão. 0 que já seria algo revolucionário para os nossos dias. Em tendo conquistado, portanto, tal situação, poder-se-á imaginar e praticar saltos mais significativos rumo a - quem sabe? - algo mais radical.

"Trabalhadores de todo o mundo, uni-vos"!

K. Marx \& F. Engels (1848)

\section{REFERÊNCIAS}

ABBAGNANO, Nicola. Dicionário de filosofia.

São Paulo: Martinsfontes, 2014.

ABREU, Maurício de Almeida. Estudo geográfico da cidade no Brasil: evolução e avaliação (contribuição à história do pensamento geográfico brasileiro), Revista Brasileira de Geografia, Rio de Janeiro, v. 56, n. 1/4, pp. 21-122, 1994.

ARAÚJO, Tânia Bacelar de. Ensaios sobre o desenvolvimento brasileiro. Heranças e urgências. Rio de Janeiro: Editora Revan, 2000.

BOURDIEU, Pierre. Contrafogos: táticas para enfrentar a invasão neoliberal. Rio de Janeiro: Jorge Zahar Editor, 1998.
CARNOY, Martin. Estado e teoria política.

Campinas: Papirus, 1988.

CASTELLS, Manuel. La question urbaine. Paris:

F. Mapero, 1972.

. Redes de indignação e esperança:

movimentos sociais na era da internet. Rio de Janeiro: Zahar, 2013.

CASTILHO, Cláudio Jorge Moura de.

Movimentos sociais: a difícil tarefa de definilos. Revista Movimentos Sociais e Dinâmicas Espaciais, v. 2, n. 1, pp.04-23, 2013.

. Uma análise geográfica da evolução dos

movimentos de bairro em Recife-PE: um movimento social vivo e relevante. Revista 
Movimentos Sociais e Dinâmicas Espaciais, v. 4, n. 1, pp.11-45, 2015.

CASTORIADIS, Cornelius. $A$ ascensão $d a$ insignificância. São Paulo: Paz e Terra, 2002. (As encruzilhadas do labirinto, IV)

CHAUÍ, Marilena. Convite à filosofia. São Paulo: Editora Ática, 1999.

FOUCAULT, Michel. Microfísica do poder. Rio de Janeiro: Graal, 1990.

GOHN, Maria da Glória. Teorias dos movimentos sociais. Paradigmas clássicos e contemporâneos. São Paulo: Edições Loyola, 1997.

GRAMSCI, Antonio. Seletions from prison notebooks. New York: International Publishers, 1971. . Note sul Machiavelli, sulla politica e sullo Stato. Roma: Riuniti, 1975. . A revolução contra "O Capital”, in: SPRIANO, Paolo. Scritti politici. (org.) Roma: Riuniti 1978. . Os intelectuais e a organização da cultura. Rio de Janeiro: Civilização Brasileira, 1987. HARVEY, David. Espaços de esperança. São Paulo: Edições Loyola, 2004. . Rebel cities: from the right to the city to the urban revolution. London: Verso, 2012.

LEFBVRE, Henri. Le droît à la ville. París: Éditions Anthropos, 1968.

MARX, K. \& ENGELS, F. Manifesto do partido comunista. Rio de Janeiro: Livraria Editora Cátedra, 1987 [1847].

MATOS, Francisco José Sobreira. Sociedades conectadas e direito à cidade: novas fronteiras dos movimentos sociais no século XXI. In: VIEIRA, Luiz Vicente. (org.) Conquistas coletivas na América Latina: o futuro dos movimentos sociais. Recife: Editora UFPE, 2015.

PONTES, Beatriz Maria Soares. Movimentos de resistência socioterritoriais pretéritos e contemporâneos: América do Norte, América do Sul e África. Revista Movimentos Sociais e Dinâmicas Espaciais, v. 5, n. 2, pp. 6-103, 2016.

. Os suportes epistemológicos dos movimentos sociais. Revista Movimentos Sociais e Dinâmicas Espaciais, v. 4, n. 1, pp. 4685, 2015.

POULANTZAS, Nicos. L'État, le pouvoir, le socialisme. París: Presses Universitaires de France, 1978.

RIBEIRO, Darcy. $O$ povo brasileiro. A formação e o sentido do Brasil. 3a edição. São Paulo: Global Editora, 2015.

SANTOS, Milton. O espaço do cidadão. São Paulo: Nobel, 1987. . A natureza do espaço. Técnica e tempo. Raão e emoção. São Paulo: Hucitrec, 1997. . Por uma outra globalização. Do pensamento único à consciência universal. Rio de Janeiro: Record, 2000.

SCHERER-WARREN, Ilse. 0 caráter dos novos movimentos sociais. In: SCERER-WARREN, Ilse \& KRISCHKE, Paulo J. (org.) Uma revolução no cotidiano? Os novos movimentos sociais na América do Sul. São Paulo: Brasiliense, 1987.

SCHERER-WARREN, Ilse. Redes de movimentos sociais. São Paulo: Edições Loyola, 1996.

SCHWARCZ, Lilia M.; STARLING, Heloisa M. Brasil: uma biografia. São Paulo: Companhia das Letras, 2016. 